This item was submitted to Loughborough's Research Repository by the author.

Items in Figshare are protected by copyright, with all rights reserved, unless otherwise indicated.

\title{
Effective and eco-friendly lubrication protocol using nanodiamonds in a dry regime for conveyor systems in the beverage industry
}

\section{PLEASE CITE THE PUBLISHED VERSION}

http://dx.doi.org/10.1002/pts.2294

\section{PUBLISHER}

(c) Wiley

\section{VERSION}

AM (Accepted Manuscript)

\section{PUBLISHER STATEMENT}

This work is made available according to the conditions of the Creative Commons Attribution-NonCommercialNoDerivatives 4.0 International (CC BY-NC-ND 4.0) licence. Full details of this licence are available at: https://creativecommons.org/licenses/by-nc-nd/4.0/

\section{LICENCE}

CC BY-NC-ND 4.0

\section{REPOSITORY RECORD}

Torres, Carmen, and Nikolaos Balodimos. 2019. "Effective and Eco-friendly Lubrication Protocol Using Nanodiamonds in a Dry Regime for Conveyor Systems in the Beverage Industry". figshare. https://hdl.handle.net/2134/24298. 
Effective and eco-friendly lubrication protocol using nanodiamonds in a dry regime for conveyor systems in the beverage industry

\begin{abstract}
Conveyor belts play an important role in the production process. Their efficiency and lifespan are strongly influenced by the use of appropriate lubrication systems, cleaning procedures and operator handling. Overuse of chemicals and detergents can result in belt degradation and corrosion. Excessive friction between the packages and the load bearing surface of the conveyors (e.g. belts or chains) can wear the packaging, delay start-ups and increase product waste. A suitably lubricated conveyor system increases longevity and promotes operational reliability. However this has traditionally been achieved by using large amounts of water and harsh detergents. The solution proposed in this study comprises the formulation of a nanodiamond particle-loaded food-grade lubricating oil, a nanolubricant, for use on packaging transport and conveyor systems. Deployed in a 'dry' regime, the nanolubricant is hydrophobic, its viscosity is suitable to be sprayed and a long shelflife ensures stable dispersions. Tribological performance on HDPE conveyor belts transporting aseptic carton packs was studied. When using the nanolubricant, wearing on the packages was reduced $60 \%$ compared to no-lubricating conditions and $17 \%$ lower than current commercial solutions used for benchmarking purposes. The preparation of the nanolubricant using sonication technology presents efficiencies and carbon footprint reductions derived from lower energy consumption in the production process. This nanolubricant is an environmentally friendly solution for the maintenance of machinery for packaging and transporting and a novel mechanism to curb product returns due to aesthetic and structural damages on the packaging.
\end{abstract}

Keywords - beverage conveyor system, lubrication, machinery maintenance, nanodiamond, environmental, food and drink

\title{
1. Introduction
}

Cans, aseptic carton packs (e.g. Tetra Pak ${ }^{\circledR}$ and SIG Combibloc packages), plastic and glass bottles and jars are often processed on mechanized conveyor systems which are lubricated to reduce friction between the packaging and the load bearing surface of the conveyor. Filling, capping, labelling, sealing, packing and discharge stations on beverage processing lines, helical conveyor tracks (i.e. lifting between levels) and buffering tracks that regulate flow of packages are areas in the factory where in occasions these containers remain unintentionally stationary for long periods of time due to start/stop occurrences in preceding or subsequent stations. 
Belts and chains move linearly underneath these packages potentially producing damages (e.g. scaring, scratches, scuffing, peeling off) to the packages which result in production loss and waste. Milk, sauces and soft drinks cartons, fizzy drinks cans and alcohol and spirits bottles compete in the very crowded market of fast moving consumer goods and any defect on the packaging or label is perceived as detrimental to the brand [1]. In order to avoid undesirable flaws caused by the transport in the filling/packaging lines, lubrication solutions are applied.

2. State of the technology: Lubrication systems in the packaging industry Both solid and liquid lubrication approaches are currently in practice in the food processing, beverage, brewing and distilling industries and have been classified in Table 2. The former include the so-called 'running dry', i.e. low friction coated and/or polymeric materials for the conveyor surfaces [2], and solid particles (e.g. graphite, PTFE and metal dichalcogenides [3] (i.e. $M X_{2}$, where $M$ is, for instance, molybdenum (Mo) or tungsten (W) and $X$ is sulphur (S) or selenium (Se)) scattered or sprayed onto the surfaces subject to friction [4]. The main drawbacks of the 'running-dry' group are the large coefficients of friction, despite the low-friction surfaces compared to lubricated surfaces, which consequently increases energy consumption and carbon footprint, and the presence of the slip-stick phenomenon. These diminish operational reliability in the process line with packages dropping out of the line and the corresponding down time. They are also specific to container-conveyor material pairs rendering them less flexible in their use within the industrial setting. On the other hand, the solid particles require frequent reapplication of the powders to the conveyors. As they tend to stick to the containers, they have to be cleaned regularly. The coating is suitable for heavy load mechanical applications but not considered safe for food contact applications.

The liquid lubricants commonly used on the conveyor systems can be classified into two main groups: 'wet' and 'dry' ${ }^{1}$, with an intermediate subgroup known as 'semi-dry' or 'half-wet'. The difference between these groups resides in the quantity and application rate of liquid sprayed, pumped or spread onto the lubricated surfaces. Good lubricity to reduce coefficient of friction and wear, low viscosity which allows easy application (via spraying or pumping), and compatibility with the beverage packaging material are the most sought after specifications in the liquid lubricating system. Compatibility is important because it is not desired that the package suffers damage or cracking in transit or in storage, or solid precipitates form when content and lubricant come into contact in the event of spillage.

(i) Wet regime lubricants: water only or water-soap mixes which contain fatty acids and alpha-olephin sulfonates (of dilution ratios 100-500 parts of water to 1 part of

\footnotetext{
${ }^{1}$ Industry practice refers to 'dry' regimes and this should not be confused with the 'running dry' condition described above
} 
concentrated lubricant) are typically sprinkled or sprayed onto the conveyor surfaces [5] in a continuous fashion or at least $50 \%$ of the operating time (ratio 2:1, not applied:applied). The main drawbacks in using these lubricants are the large amounts of water used, their germ promoting character, and when containing soap, their uncontrolled foaming which derives onto package flow control problems, poor biodegradability (as they contain solvents, EDTA- a metal stabiliser - or other chelating agents to compensate for the hard cations present in water $\left(\mathrm{Ca}^{2+}\right.$ and $\left.\mathrm{Mg}^{2+}\right)$ and avoid their precipitation), $\mathrm{pH}$ and temperature-dependant performance [6, 7]. Antimicrobial agents (e.g. amines) added to prevent slime formation has been found to be deactivated by the presence of the fatty acids. The presence of surfactants as thinning ingredients to reduce soap viscosity has been seen to produce further precipitates which results in lubricity reduction [8]. The excess of water makes necessary the use of drip pans and overflow trays to contain spillages which carries the added inconvenience of factory floor safety. Although typically 'wet' lubrication is of aqueous nature, oils and greases may also fall within this category if the amounts used for lubrication are such that the surfaces are wetted thoroughly creating elastohydrodynamic and full film lubrication systems. Their use is becoming less common in conveyor systems in the beverage and packaging industry given their residues and smearing on containers and labels.

(ii) Dry regime lubricants: aqueous or non-aqueous fluids, oils, oil mixtures and oilparticle emulsions and dispersions typically applied intermittently through dispensing or spraying nozzles without dilution. The dispensing rate can further divide the dry lubricants into 'semi-dry' (or 'half-wet'), when the rate is larger than 2:1 and less than $32: 1$, or 'dry' regime when the application ratio is larger than 32:1 (not applied:applied time)[9]. The 'dry' lubricants, because they are more concentrated (typically $<50 \%$ of dispersant [10]) and because water use is minimal, compensate the drawbacks presented by the 'wet' regimes. This application has become very popular in recent years. However, most of the lubricants applied in the 'dry' regime still suffer from being specific to each application. For example, silicone-based [10] and fluorine-containing lubricants [11] are good performers with PET bottles (i.e. containers made of ethylene terephthalate homopolymers, copolymers and mixtures) but less effective on glass and metal containers, particularly on a metal surface [10]. Silicone with fatty amines dispersed in a 'semi-dry' regime are recommended for glass on stainless-steel [9]. Lubricants that contain amines, alcohols, potassium hydroxide, ammonium salts or mixtures are incompatible with PET containers causing them to crack in transit or storage [12-14]. Polytetrafluoroethylene (PTFE) particles of the micro scale are mixed with mineral oils to be used as lubricants in cartons conveying belts. Applied by brushes and nozzles, PTFE adheres very strongly to the chains and this soiling curb the performance profile of the lubricant gradually [15]. In addition, PTFE has also been shown to produce stress-cracking in PET bottles [11].

\subsection{Nanoparticle-containing lubricants}


In the most recent years the nanoparticle-containing suspensions have surged as promising lubricants. Although the majority of examples are oil-based, there are also examples of water-based lubricants [16]. The nanometre scale of the particles improves solubility into the oils, compared to the micro scales [17]. The lubrication mechanism promoted by nanoparticles is a physical effect [36]. The nanoparticles act as spacers and produce ball [37] and sliding effects [38] via mechanical entrapment of the particles between the rubbing surfaces (e.g. through exfoliation and third body transfers [39]).

Nanodiamond is a nanoparticle already reported for its lubrication properties which shows a promising future as a lubricant component for the food technology. Its carbon chemistry biodegradability, non-toxicity [44], bearing-like shape promoting rolling as lubrication mechanism [45], solubility in both mineral oil and others $([31,46]$ and feasible production into de-agglomerated [47, 48] and stable dispersions [49] (via the detonation method [50-53]) makes it a suitable candidate for formulations designed for the use in the mechanical services in the food factory and for the occasional contact with food materials and containers (namely H1 USDA approved).

In the present study we focused on the development of a new lubrication solution which surmounts the disadvantages of the current lubrication approaches with the following specifications: (1) liquid lubrication in the 'dry' regime, therefore the use of lubricant is minimal but effective, stirring away from the many disadvantages of the 'wet' lubrication regimes and offering an eco-friendly alternative; (2) nanoparticles were used as lubricating agents, given the environmental advantages derived from its chemistry; and (3) the production process of the nanolubricant was energy- and cost-efficient, when compared to traditional methods. The following sections of this paper introduce the formulation of the nanodiamond particle-loaded food grade oil, the nanolubricant, its characterisation and testing. Its tribological performance on aseptic carton packs travelling on a HDPE conveyor belt is reported. Carton packs were selected as being largely present in conveyor lines around the world. A commercial lubricant was used as a benchmark. Industrial scale container transport equipment and typical working conditions were chosen to simulate a realistic factory setting. The last section is dedicated to the novel production methodology devised for the nanolubricant, along with its ageing and stability studies before conclusions are drawn.

\section{Experimental}

\subsection{Materials}

The nanodiamond particles used in this study were purchased from Adámas Nanotechnologies (USA). The nanoparticles were synthesised by the detonation method [52] and then aggregated to a range of 10-30nm (noted in this study as slurry ' 30 ') and $<5 \mathrm{~nm}$ (noted as slurry '5'). The nanodiamonds were supplied as a 
slurry containing also additives (molybdenum di)2-ethylhexyl) phosphoridithioate [54] and a fluorinated stabiliser [55] in proportions proprietary to the company. A commercial oil (Kristol M24, a white mineral oil (Petrochem Carless Ltd, United Kingdom) was used as the base oils without further treatment. Nanolubricant samples were prepared by dispersing $0.01 \% w t$ ratio of nanodiamonds in the base oil. This concentration was informed by previous studies [54].

\subsection{Materials Characterisation}

The nanoparticle population in the slurry was characterized using a Nanosight LM-10 instrument (Malvern Instruments Ltd, UK) and its stability (i.e. zeta-potential and conductivity) measured using a Zetasizer Nano ZS (Malvern, UK). The zeta-potential is a measure of the surface charge and a large (absolute) value indicates high surface charge, strong particle repulsion and high stability of the nanoparticles in the solution. The zeta-potential resulted in $-116 \mathrm{mV}$ with a conductivity of $4.12 \mu \mathrm{S} / \mathrm{cm}$ and electrophoretic mobility of $-6.83 \mathrm{e}-3 \mu \mathrm{m} . \mathrm{cm} / \mathrm{Vs}$, values that confirmed full stability of the dispersions. The properties of the oil are listed in Table 1. The rheological characteristics of the nanolubricants were measured using a Brookfield Rheometer DV-II+ Pro with a RV-1 spindle at a spindle speed of 60rpm. The dynamic viscosity (in $\mathrm{CP}$ ) of the nanolubricants could be fitted to linear relationships against the temperature (in ${ }^{\circ} \mathrm{C}$ ) of the form $<y=48.317-0.415 . x>$. The measurements within the range $\left[20-100^{\circ} \mathrm{C}\right]$ yielded a linear relationship between the dynamic viscosity and the temperature. The size of the nanoparticles did not affect these coefficients. This viscosity value was within the range of ISO VG32 (typical industrial application oil) and appropriate for the lubricant to be applied by spraying in a dry lubrication regime maintaining in this way a high degree of system cleanliness in application below and above the conveyor line.

\subsection{Study of the tribological performance on the conveyor belts}

\subsubsection{Methodology}

A high density polyethylene (HDPE) industrial-sized conveyor was used for testing friction and wearing (or scuffing) on the bottom of aseptic cartons typically found in the packaging and filling food industries (mass $1.088 \mathrm{~kg}$, contact area onto belt $72.60 \mathrm{~mm} \times 70.60 \mathrm{~mm}$ ). The belt travelled at a speed of $20 \mathrm{~m} / \mathrm{min}$ and the tests were run for $60 \mathrm{~min}$ (Figure 1). This timeframe corresponds to a long term residence time typically observed in industrial settings with abrupt flows which originates the larger incidence of package damage and customer complaint. K-type thermocouples were fitted to the carton/conveyor interface for monitoring purposes. A set of tests was run without any lubrication (labelled as 'blank'). When lubricants were present, these were sprayed onto the conveyor belts in 'dry-regime' conditions (i.e. >32:1) on top of the chain (comprising $50 \% \mathrm{vol}$ of the amount) and on the wear strips (comprising $25 \% \mathrm{vol}$ each) for a total amount of $8 \mathrm{ml}$ consumed during $60 \mathrm{~min}$. The lubricants tested were nanolubricants comprising the dispersion of nanodiamonds in the 
mineral oil: 30nm ('Min30') and 5nm ('Min5'). Commercial lubricant RM2000T was also tested for benchmarking purposes. RM2000T is a PTFE-based food grade lubricant with a suspension in mineral oil of particles in the micro scale which has been in the market since 1999 and it is broadly used in bottling and Tetra-Pak ${ }^{\mathrm{TM}}$ filling lines. As a comparison, the tribological properties of the base oil without carrying the nanodiamonds or additives, in their pure form, were also evaluated (labelled 'Min').

The friction force was measured by means of the sliding force of the conveyor when the packages were under motion-restricted mode. A digital force gauge (Mecmesin Ltd, UK) collected sliding forces at a $10 \mathrm{~Hz}$ sampling rate as shown in Figure 1 . This allowed the calculation of the coefficient of friction (COF) using equation (1), with force $\mathrm{F}$ being the load $(\mathrm{N})$ registered by the force gauge, ' $i$ ' the number of packs, $g$ the gravitational constant $\left(\mathrm{m} / \mathrm{s}^{2}\right)$ and mass $\mathrm{m}$ the average value $(\mathrm{kg})$ of the packs used in each run.

$$
C O F=\frac{F}{i \cdot g \cdot m}
$$

The wear scar surfaces on the bottom of the packages were inspected by high resolution scanning (2400dpi) on and EPSON Perfection Scanner 1640SU (Figure 2) and the results analysed with Image J (W. Rasband, 1997, National Institutes of Health, USA), a java-based open-source software for image processing and analysis. Statistical analysis: COF tests were obtained from 5 different experiments. Wear tests were conducted on 6 specimens per test. Both are expressed as means \pm standard deviation (SD). Differences amongst the groups were analysed by the t-test for paired samples for means and hypothesised a normal distribution. A p-value of $\leq 0.05$ was considered to indicate statistically significant differences.

\subsubsection{Results}

The coefficient of friction (COF) for each of the packages as a function of time for each of the lubricating fluids including the 'blank' is plotted in Figure 3. Temperature was monitored throughout the tests with no significant changes (data not shown). The results of the measurements for the COF and the wear scar area are summarised in Figure 4 and Table 3. Results from the t-test that hypothesised a paired relationship between the COF and the wear scar results yielded a Pearson coefficient of 0.935 and a p-value 0.05 , which confirms the correlation within the limits for a confident statistical significance. As it can be seen in Figure 3, maximum COF values (0.269-0.221) were reached when there was no lubricating fluid present (i.e., in 'blank' conditions). In the presence of lubrication, COF values were reduced generally for all the lubricating fluids, as per Table 3. 


\subsubsection{Discussion}

Aseptic cartons (Figure 3) presented an increasing COF value with time for all the lubricants which is typical when the boundary layer is the dominant regime of lubrications (i.e. the lubricating fluid film thickness is small and asperities from rubbing surfaces come into contact and wear is high). It remained stable throughout the duration of the friction test in all cases. In the 'running-dry', non-lubricant conditions ('blank') there was an initial drop in the COF (0-15min) and this is attributed to a 'waxification' (i.e. third body transfer - plastic film particles- from the package onto the transporting belt and or the lubricant) of the conveyor, since there was material removed from the cartons (Figure 2). In the presence of mineral oil and 30nm-loaded mineral oil the COF reached a plateau at approx. 10mins (Mineral) and 15mins (Min30) indicating a stable boundary layer regime of lubrication, although the COFs for the nanodiamond-loaded oil is $19 \%$ smaller compared to the base oil. This observation reinforces the hypothesis of the 'ball-bearing' effect produced by the nanoparticles that ease the travel of the packages over the conveyor, in that way protecting from solid-to-solid abrasion (Figure 5a). This plateau was not reached with the RM2000T or the 5nm-loaded mineral oil which presented an ascending trend for the COF throughout the length of the test. This indicates that in the presence of these two lubricating fluids, there was no self-organisation of the particles which did not agglomerate further to create a local ball-bearing effect on the lubricating regime. The micro-scale particles present in RM2000T were too large to maintain a stable self-organisation that contributed to forming an effective lubricating layer (Figure 5b). The comparison between $5 \mathrm{~nm}$ and $30 \mathrm{~nm}$ suggests that the former are too little particles which do not form agglomerates large enough to create a boundary layer (Figure 5c). An episode of rupture in the sliding layer can be observed in the experimental results and it is indicated with a blue arrow in Figure 3.

The results obtained from the mineral oil used as a lubricant present a lower COF value with respect to the 'blank' conditions. However, the wear scar area is the largest of all cases, including when no lubricating fluid was present. The bottoms of the cartons were seen to soak in the oil through the torn outer plastic layer into the deeper layers, affecting the aesthetics of the packaging. The red arrow in Figure 3 shows an event of sudden increase for the COF which is suspected to have provoked the further tearing on the bottom of the package. Therefore, it can be concluded that beyond a value of COF $>0.121$, the packaging gets damaged substantially. The COF values for the other lubricating fluids were below this level and therefore the oil soaking phenomenon was not present.

3.4 Study on the stability of the dispersion comparing production methods

\subsubsection{Methodology}


Two methods were devised to prepare the nanolubricants (i.e. the nanodiamondsloaded lubricating oil): (i) mixing: the particles were mixed into the oil and stirred continuously for $5 \mathrm{~min}$ at $65^{\circ} \mathrm{C}$; (ii) sonication: the particles suspended in an equal quantity of oil were subjected to an ultrasonic sonication regime of $170 \mu \mathrm{m}$ peak to peak for a duration in the range of 5 to 15 s or until the suspension was transparent. Temperature was controlled so it would not excess $65^{\circ} \mathrm{C}$. The slurry chosen for this work was the $<30 \mathrm{~nm}$ particle size. Nanodiamond dispersions were prepared by both the mixing and the ultrasonic sonication methods. The power consumption in each operation was measured with a domestic energy monitor (Eco-eye real-time electricity monitor, UK). The dispersions were aged (i.e. fluid stored stationery) for an excess of 17 weeks (120days). The stability of the suspensions prepared (particle size population distribution on fresh and aged dispersions) was monitored both visually and also using the Malvern Nanosight LM-10 instrument to capture 5x60s videos at $30 \mathrm{fps}$ per sample.

\subsubsection{Results}

Visual monitoring on the samples confirmed clear and transparent nanolubricants during the aging process without sedimentation of nanodiamond aggregates. To confirm the absence of agglomerated nanoparticles, particle size measurement and analysis were carried out on recently prepared samples (labelled as 'fresh') and on stored samples (120+days, labelled 'aged'). The results are presented in Figure 6.Power consumption values in the sonication process were $3 \%$ of those in the mixing process for an equal amount of oil treated.

\subsubsection{Discussion}

From a shelf-life viewpoint aging did not seem to have a significant impact and all suspensions remained stable and deagglomerated (agglomerates size $<30 \mathrm{~nm}$ ) after $120+$ days. With regards to both production methods, the sonication showed to create dispersions of a smaller mean agglomerate size when compared to the mixing. The dispersion of the aged sonicated samples presented more variation and a wider particle size distribution bell compared to the mixing. However, the efficacy of the sonication method versus the mixing is demonstrated because of the advantage of a short and cold process versus the traditional slow mixing. The savings in power consumption were largely derived from the fact that the oil was not heated in the sonication process. The heating operation was typically an order of magnitude larger than the mixing alone.

\section{Conclusions}

Safeguarding the integrity of packages when these are travelling long distances on belts or when they suffer unexpected stops in filling/packing stations is crucial to prevent product returns and loss of consumer confidence. Appropriate lubrication of 
the food-processing conveyance system is important as well as considering environmental factors in the operation and maintenance of the transport machinery. In this study the formulation, testing and shelf-life characterisation of a nanolubricant prepared with nanodiamonds dispersed in commercial mineral oil was studied. Its 'dry' regime application and non-aqueous nature presents advantages when compared with traditional wet, water-based, bacterial-growth prone approaches to lubrication. Tribological performance of the nanolubricant has been assessed on a factory-sized set-up using commonly used aseptic carton packs as the packages travelling on the conveyor system. Friction and wear tests under load conditions were conducted. The nanolubricants present a good behaviour with respect to nonlubricated conditions and other commercial lubricants currently used in the food and drink industry. It is suggested that the nano-sized particles promote an effective 'ballbearing' effect between the surfaces in contact (e.g. the surface between the chain and the package). The nanolubricant prevents from reaching large values of coefficient of friction and therefore extensive wearing. The main advantage in the use of the nanolubricant is to avoid the tearing of the package walls and prevent the 'soaking in' of the lubricant onto the deeper layers of the carton packs. This phenomenon is particularly poignant if the content is of a high pressure vapour nature (e.g. alcohol) since this event can precipitate structural damage of the package due to extensive wicking and soaking of the package multi-layered walls. The predominant regime of lubrication was boundary film and the solid-solid friction mechanisms observed were plastic deformation and adhesion bond/third body transfer. Further environmental benefits arise from the novel preparation protocol for the dispersions. The sonication method (fast and with no need of heat treatment) delivered stable suspensions in the shelf-life studies.

This work has shown how to produce stable and long shelf-life suspensions of nanodiamonds in a food-grade lubricating oil for the direct application onto typical conveyor systems in a packaging factory. The results from this study are useful to packaging industry managers and operators because they show the advantages of using a nanolubricant deployed in a 'dry' regime fashion, an environmentally friendly solution with no water wasted and no harmful soapy and solvent effluents onto the industrial sewage system which also reduces stock costs. In addition to this, an additional recommendation is to explore the application of lubrication products that contain nanodiamonds due to their effective performance and biodegradability.

Future work will address the tribological studies of this newly formulated nanolubricant on other conveyor systems and packages such as cans, plastic and glass bottles to assess full compatibility amongst all constituents of the conveying system. 
Acknowledgements

The authors are grateful to Innovate UK for their grant KTP9434 which has supported this work. Mr Charles Brunton and his team at Specialist Lubricants Ltd have been instrumental in carrying out the tests conducted on the conveyor belts.

\section{References}

1. Caner, C. and M.A. Pascall, Consumer complaints and accidents related to food packaging. Packaging Technology and Science, 2010. 23(7): p. 413-422.

2. Unal, H., S.H. Yetgin, and F. Findik, The effect of applied load and sliding speed on the tribological properties of Nylon 6 and ultra-high-molecularweight polyethylene. Industrial Lubrication and Tribology, 2014. 66(3): p. 498504.

3. Rapoport, L., et al., Hollow nanoparticles of WS2 as potential solid-state lubricants. Nature, 1997. 387(6635): p. 791-793.

4. Scharf, T.W. and S.V. Prasad, Solid lubricants: a review. Journal of Materials Science, 2013. 48(2): p. 511-531.

5. Wilson, C.M. and R.B. Barrett, Conveyor lubricating system, US 4262776 A, 1981.

6. Schmidt, B.E. and R.E.F. Swerts, Antimicrobial lubricant composition containing a diamine acetate, US5182035 A, 1993.

7. Grosse, B.W., et al., Lubricants based on polysiloxane and the use thereof, WO2001018160 A2, 2001.

8. Stanton, J. and D. Garvin, Improved aqueous soap-based lubricant composition, WO1981000014 A1, WO1981000014 A1, 1981.

9. Chamblee, K.W., et al., Conveyor lubricants including emulsions and methods employing them, PCT/IB2011/054184, 2012.

10. Valencia, S.A.S., et al., Lubricant for conveying containers, WO2007094980 A2, WO2007094980 A2, 2007.

11. Grosse, B.W., et al., Anti-friction lubricants containing fluorine, WO 2001018157 A2, 2001.

12. Li, M., et al., Antimicrobial lubricants useful for lubricating containers, such as beverage containers, and conveyors therefor, PCT/US2000/017525, WO2001023504 A1, 2001.

13. McSherry, D.D. and G.J. Wei, Fatty amide ethoxylate phosphate ester conveyor lubricant, US5925601 A, WO2000022073 A1, 1999.

14. Despo, A.D., Lubricant for transport of P.E.T. containers, US5391308 A, 1995.

15. Scheld, J.L., PTFE oil coating composition, US 5160646 A, 1992.

16. Wang, J., et al., Tribological properties of water - soluble TiO2 nanoparticles as additives in water. Industrial Lubrication and Tribology, 2010. 62(5): p. 292297.

17. Padgurskas, J., et al., Development and modification of Fe and FeCu nanoparticles and tribological analysis of the lubricants with nano suspensions. Industrial Lubrication and Tribology, 2012. 64(5): p. 253-257.

18. Tarasov, S., et al., Study of friction reduction by nanocopper additives to motor oil. Wear, 2002. 252(1-2): p. 63-69. 
19. Hu, Z.S. and J.X. Dong, Study on antiwear and reducing friction additive of nanometer titanium borate. Wear, 1998. 216(1): p. 87-91.

20. Zhang, Y., et al., Synthesis and tribological properties of oil-soluble copper nanoparticles as environmentally friendly lubricating oil additives. Industrial Lubrication and Tribology, 2015. 67(3): p. 227-232.

21. Hisakado, T., T. Tsukizoe, and H. Yoshikawa, Lubrication Mechanism of Solid Lubricants in Oils. Journal of Lubrication Technology, 1983. 105(2): p. 245252.

22. Kumar Dubey, M., J. Bijwe, and S.S.V. Ramakumar, PTFE based nanolubricants. Wear, 2013. 306(1-2): p. 80-88.

23. Hu, Z.S. and J.X. Dong, Study on antiwear and reducing friction additive of nanometer titanium oxide. Wear, 1998. 216(1): p. 92-96.

24. Huang, Y., et al., Preparation and tribological properties of surface-modified calcium borate nanoparticles as additive in lubricating oil. Industrial Lubrication and Tribology, 2014. 66(1): p. 143-150.

25. Thakre, A.A. and A. Thakur, Study of behaviour of aluminium oxide nanoparticles suspended in SAE20W40 oil under extreme pressure Iubrication. Industrial Lubrication and Tribology, 2015. 67(4): p. 328-335.

26. Zhang, M., X. Wang, and W. Liu, Tribological behavior of LaF3 nanoparticles as additives in poly - alpha - olefin. Industrial Lubrication and Tribology, 2013. 65(4): p. 226-235.

27. Hernández Battez, A., et al., CuO, ZrO2 and ZnO nanoparticles as antiwear additive in oil lubricants. Wear, 2008. 265(3-4): p. 422-428.

28. Maliar, T., et al., Tribological behaviour of mineral and rapeseed oils containing iron particles. Industrial Lubrication and Tribology, 2015. 67(4): p. 308-314.

29. Biresaw, G. and S.M. Erhan, Solid lubricant formulations containing starchsoybean oil composites. Journal of the American Oil Chemists' Society, 2002. 79(3): p. 291-296.

30. Zhou, X., et al., Tribological properties of Cyanex 301 - modified MoS2 nano - sized hollow spheres in liquid paraffin. Industrial Lubrication and Tribology, 2008. 60(3): p. 147-152.

31. Peng, D.X., et al., Tribological properties of diamond and SiO2 nanoparticles added in paraffin. Tribology International, 2009. 42(6): p. 911-917.

32. Zhou, J., et al., Study on the structure and tribological properties of surfacemodified Cu nanoparticles. Materials Research Bulletin, 1999. 34(9): p. 13611367.

33. Zhang, Z.J., J. Zhang, and Q.J. Xue, Synthesis and Characterization of a Molybdenum Disulfide Nanocluster. The Journal of Physical Chemistry, 1994. 98(49): p. 12973-12977.

34. Tang, Z. and S. Li, A review of recent developments of friction modifiers for liquid lubricants (2007-present). Current Opinion in Solid State and Materials Science, 2014. 18(3): p. 119-139.

35. Yamamoto, Y., et al., Frictional characteristics of molybdenum dithiophosphates. Wear, 1986. 112(1): p. 79-87.

36. Lee, K., et al., Understanding the Role of Nanoparticles in Nano-oil Lubrication. Tribology Letters, 2009. 35(2): p. 127-131.

37. Wu, Y.Y., W.C. Tsui, and T.C. Liu, Experimental analysis of tribological properties of lubricating oils with nanoparticle additives. Wear, 2007. 262(7-8): p. 819-825. 
38. Chiñas-Castillo, F. and H.A. Spikes, Mechanism of Action of Colloidal Solid Dispersions. Journal of Tribology, 2003. 125(3): p. 552-557.

39. Tevet, O., et al., Friction mechanism of individual multilayered nanoparticles. Proceedings of the National Academy of Sciences, 2011. 108(50): p. 1990119906.

40. Huang, H.D., et al., An investigation on tribological properties of graphite nanosheets as oil additive. Wear, 2006. 261(2): p. 140-144.

41. Ping, L., et al., Preparation and tribological properties of complex nanoparticle styrene/calcium borate with core-shell structure. Industrial Lubrication and Tribology, 2014. 66(4): p. 525-532.

42. Xue, Q., W. Liu, and Z. Zhang, Friction and wear properties of a surfacemodified TiO2 nanoparticle as an additive in liquid paraffin. Wear, 1997. 213(1-2): p. 29-32.

43. Hu, Z.S., et al., Preparation and tribological properties of nanometer magnesium borate as lubricating oil additive. Wear, 2002. 252(5-6): p. 370374.

44. Gibson, N., et al., Colloidal stability of modified nanodiamond particles. Diamond and Related Materials, 2009. 18(4): p. 620-626.

45. Tao, X., Z. Jiazheng, and X. Kang, The ball-bearing effect of diamond nanoparticles as an oil additive. Journal of Physics D: Applied Physics, 1996. 29(11): p. 2932.

46. Chu, H.Y., W.C. Hsu, and J.F. Lin, The anti-scuffing performance of diamond nano-particles as an oil additive. Wear, 2010. 268(7-8): p. 960-967.

47. Liang, Y., M. Ozawa, and A. Krueger, A General Procedure to Functionalize Agglomerating Nanoparticles Demonstrated on Nanodiamond. ACS Nano, 2009. 3(8): p. 2288-2296.

48. Pentecost, A., et al., Deaggregation of Nanodiamond Powders Using Saltand Sugar-Assisted Milling. ACS Applied Materials \& Interfaces, 2010. 2(11): p. 3289-3294.

49. Ozawa, M., et al., Preparation and Behavior of Brownish, Clear Nanodiamond Colloids. Advanced Materials, 2007. 19(9): p. 1201-1206.

50. Yu. Dolmatov, V., Detonation synthesis ultradispersed diamonds: properties and applications. Russian Chemical Reviews, 2001. 70(7): p. 607-626.

51. Dolmatov, V.Y., Detonation nanodiamonds in oils and lubricants. Journal of Superhard Materials, 2010. 32(1): p. 14-20.

52. Mochalin, V.N., et al., The properties and applications of nanodiamonds. Nat Nano, 2012. 7(1): p. 11-23.

53. Hsin, Y.L., et al., In situ de-agglomeration and surface functionalization of detonation nanodiamond, with the polymer used as an additive in lubricant oil. Journal of Materials Chemistry, 2011. 21(35): p. 13213-13222.

54. Nunn, N., et al., Tribological properties of polyalphaolefin oil modified with nanocarbon additives. Diamond and Related Materials, 2015. 54: p. 97-102.

55. Ivanov, M.G., L.E. Deev, and O.A. Shenderova, Lubricant and synergistic additive formulation, US 20120122743 A1, WO 2011011714 A1, , 2011. 
Tables:

Table 1: Rheological properties of the base oil

\begin{tabular}{|c|c|}
\hline & Mineral oil \\
\hline Commercial name & Kristol M24 \\
\hline $\begin{array}{l}\text { Kinematic viscosity } \\
(\mathrm{mm} 2 / \mathrm{s}) 40^{\circ} \mathrm{C}\end{array}$ & 36.0 \\
\hline Pour point $\left({ }^{\circ} \mathrm{C}\right)$ & -6 \\
\hline Flash point $\left({ }^{\circ} \mathrm{C}\right)$ & 180 \\
\hline Specific gravity (at $15^{\circ} \mathrm{C}$ ) & 0.859 \\
\hline pH & 6.5 \\
\hline Colour IOdour & Colourless / Odourless \\
\hline
\end{tabular}

Table 2: Industrial lubrication regimes

\begin{tabular}{|c|c|c|c|c|}
\hline Method & Type & Application regime & Agent & $\begin{array}{l}\text { Dispersant or } \\
\text { carrier and } \\
\text { dispersion ratio } \\
\text { (carrier:agent) }\end{array}$ \\
\hline \multirow[t]{2}{*}{ Solid } & 'running dry' & $\begin{array}{l}\text { None, it relies on friction } \\
\text { properties of materials in } \\
\text { contact }\end{array}$ & none & none \\
\hline & $\begin{array}{l}\text { Solid } \\
\text { particles }\end{array}$ & $\begin{array}{l}\text { Requires frequent } \\
\text { reapplication }\end{array}$ & $\begin{array}{l}\text { Macrosized } \\
\text { solid particles }\end{array}$ & None \\
\hline \multirow{3}{*}{ Liquid } & Wet & $\begin{array}{l}\text { Continuous or at least } \\
50 \% \text { of the time, i.e. }<2: 1\end{array}$ & $\begin{array}{l}\text { Soap } \\
\text { compounds }\end{array}$ & $\begin{array}{l}\text { Water } \\
\text { (typically) } \\
\text { largely diluted } \\
{[100-500]: 1} \\
\end{array}$ \\
\hline & $\begin{array}{l}\text { Semi-dry (or } \\
\text { half wet) }\end{array}$ & $32: 1>x>2: 1$ & $\begin{array}{l}\text { Micro or } \\
\text { nanosized } \\
\text { particles }\end{array}$ & $\begin{array}{l}\text { Water or oil, } \\
\text { heavily } \\
\text { concentrated } \\
(\leq 2: 1)\end{array}$ \\
\hline & Dry & $>32: 1$ & $\begin{array}{l}\text { Micro or } \\
\text { nanosized } \\
\text { particles }\end{array}$ & $\begin{array}{l}\text { Water or oil } \\
\text { heavily } \\
\text { concentrated } \\
\text { or no dilution } \\
(\leq 2: 1)\end{array}$ \\
\hline
\end{tabular}

Table 3: Coefficient of friction and wear scar area values for the aseptic carton packages when using the lubricating fluids on the conveyors

\begin{tabular}{lll}
\hline & $\begin{array}{l}\mathrm{COF}(\mathrm{SD}) \\
(\Delta \%)\end{array}$ & $\begin{array}{l}\text { Wear, } \\
\mathrm{cm}^{2}(\mathrm{SD}) \\
(\Delta \%)\end{array}$ \\
\hline Blank & $\begin{array}{l}0.231(0.003) \\
(-)\end{array}$ & $\begin{array}{l}0.55(0.08) \\
(-)\end{array}$ \\
RM2000T & $0.113(0.003)$ & $0.31(0.11)$
\end{tabular}




\begin{tabular}{lll} 
& $(-51 \%)$ & $(-43 \%)$ \\
Min & $0.149(0.003)$ & $0.72(0.13)$ \\
& $(-36 \%)$ & $(31 \%)$ \\
Min30 & $0.121(0.002)$ & $0.22(0.08)$ \\
& $(-48 \%)$ & $(-60 \%)$ \\
Min5 & $0.114(0.003)$ & $0.26(0.05)$ \\
& $(-51 \%)$ & $(-52 \%)$ \\
\hline
\end{tabular}

*note: Coefficient of friction (COF) and Wear Scar area are averaged values with a standard deviation (std). $\Delta \%$ is the percentage of reduction (negative scalar) or increment (positive scalar) with respect to the blank tests with no lubricating fluid

Figures:

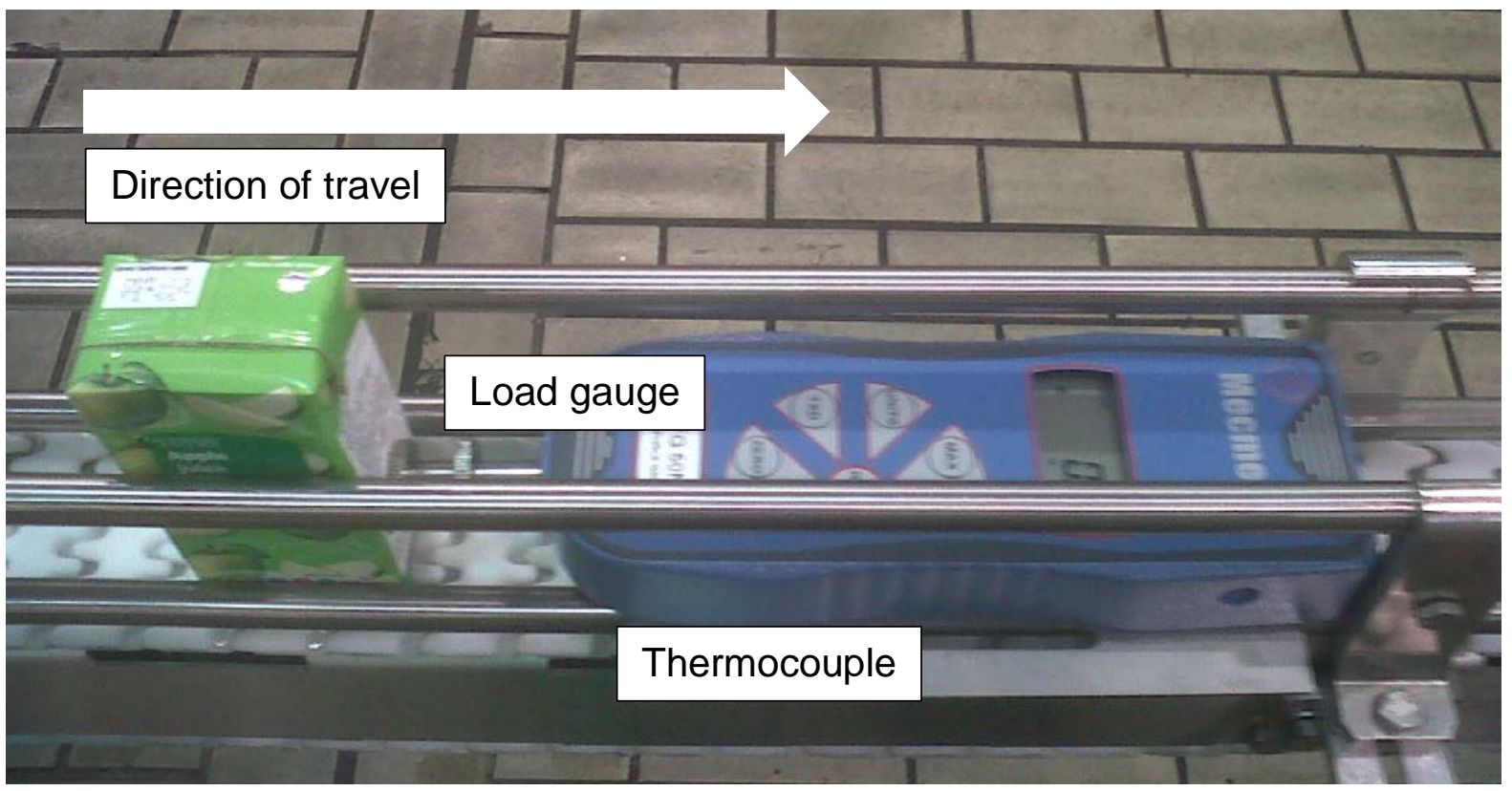

Figure 1: Experimental set up for the conveyor belt
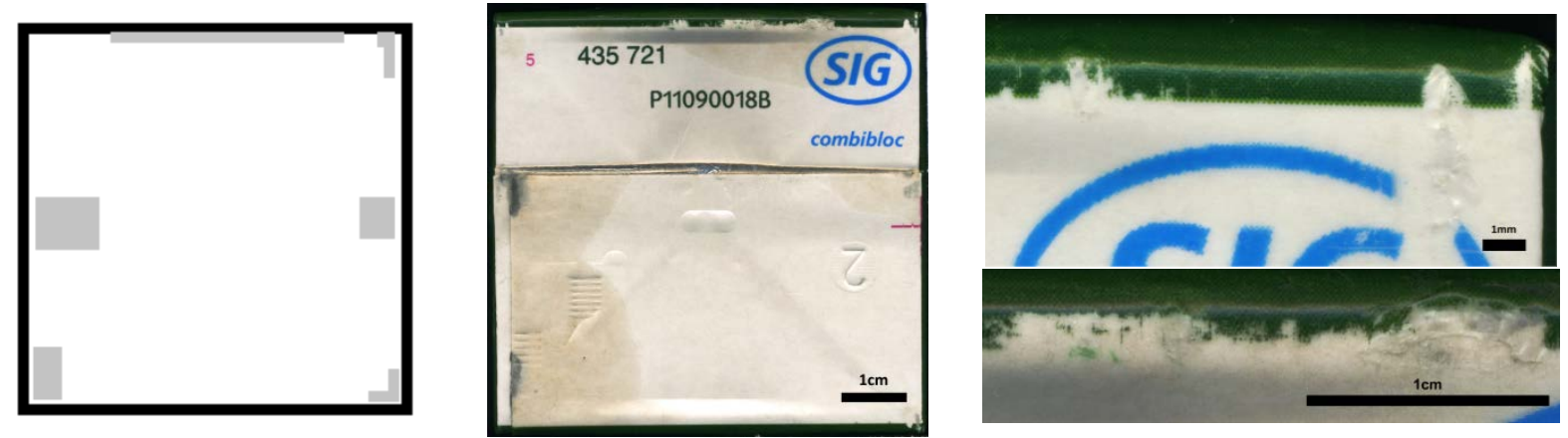

Figure 2: Representative scars and scuffing on packages used on the conveyors 


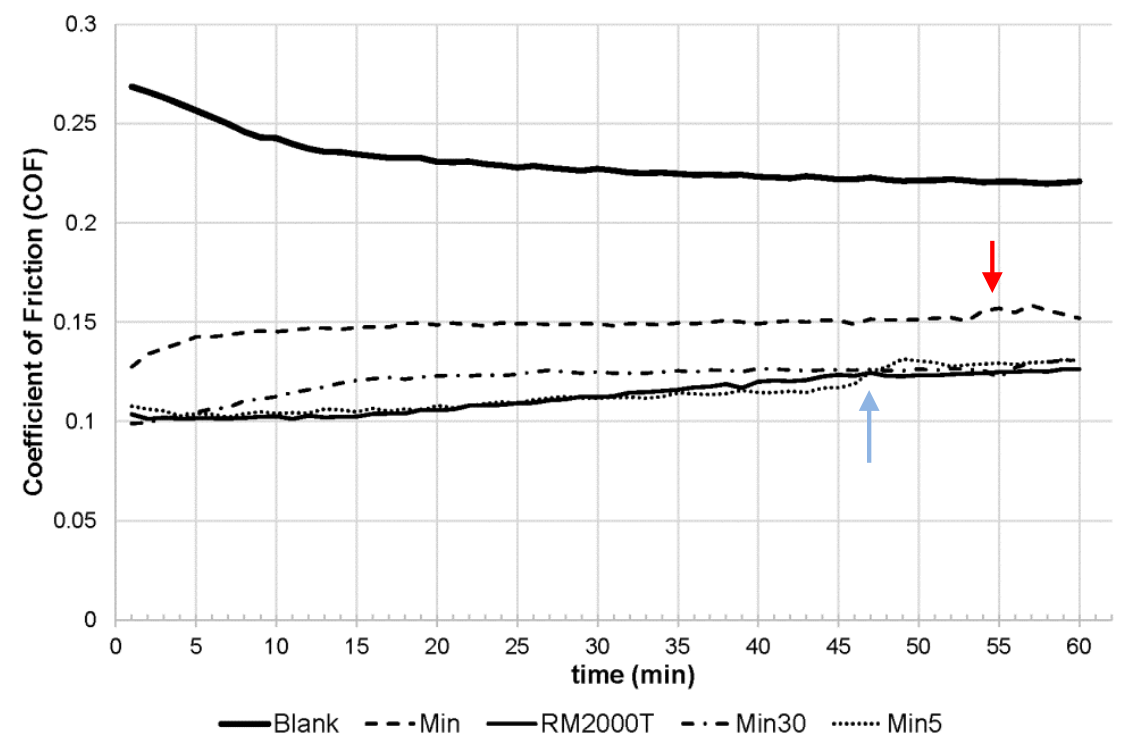

Figure 3: COF values for cartons on the conveyor system. The blue arrow represents an episode of rupture in the sliding layer and the red arrow the indication of further tearing.

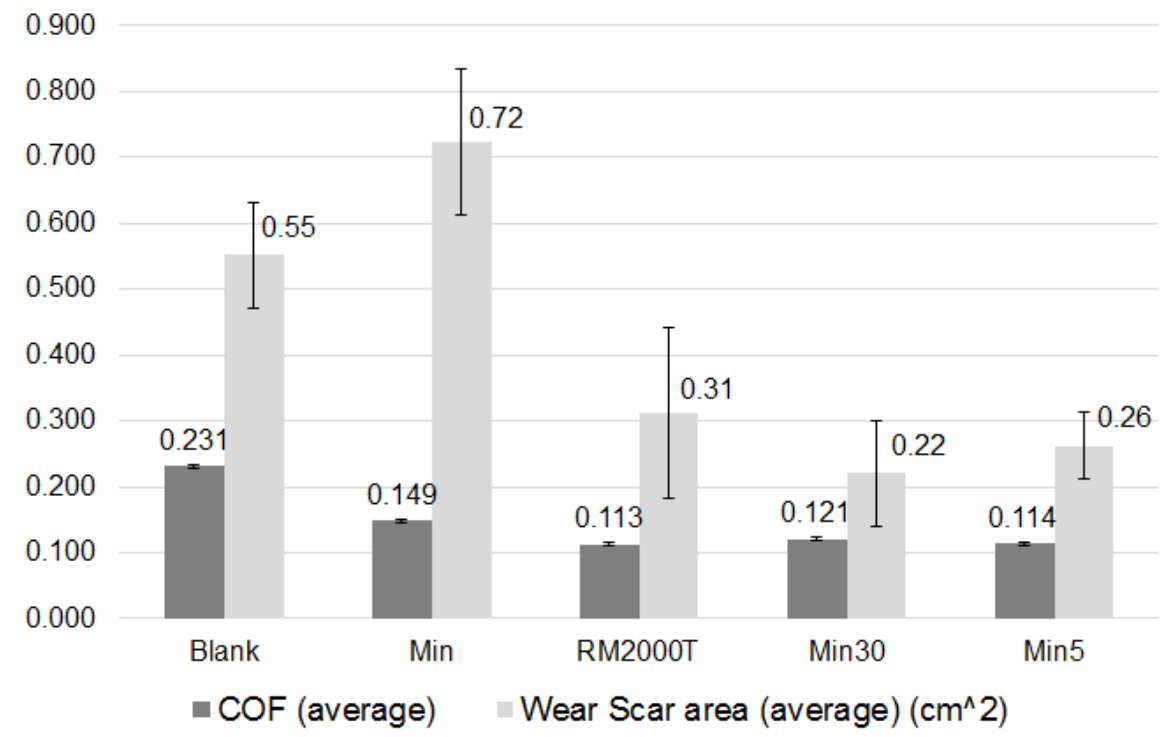

Figure 4: COF and Wear Scar area summary per lubricant type for the aseptic carton packs. Table 3 presents details in full 


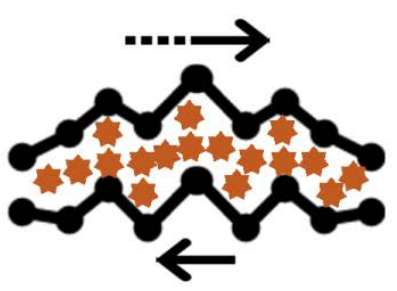

(a)

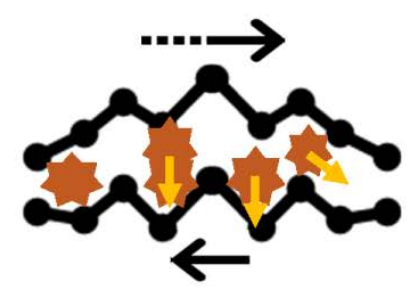

(b)

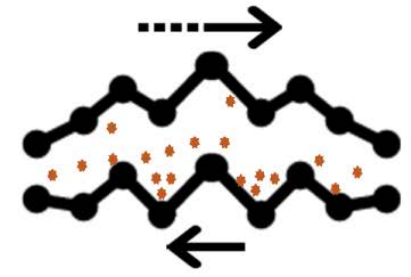

(c)

Figure 5: Schematic of nanoparticle size affecting the 'ball bearing' lubrication effect 

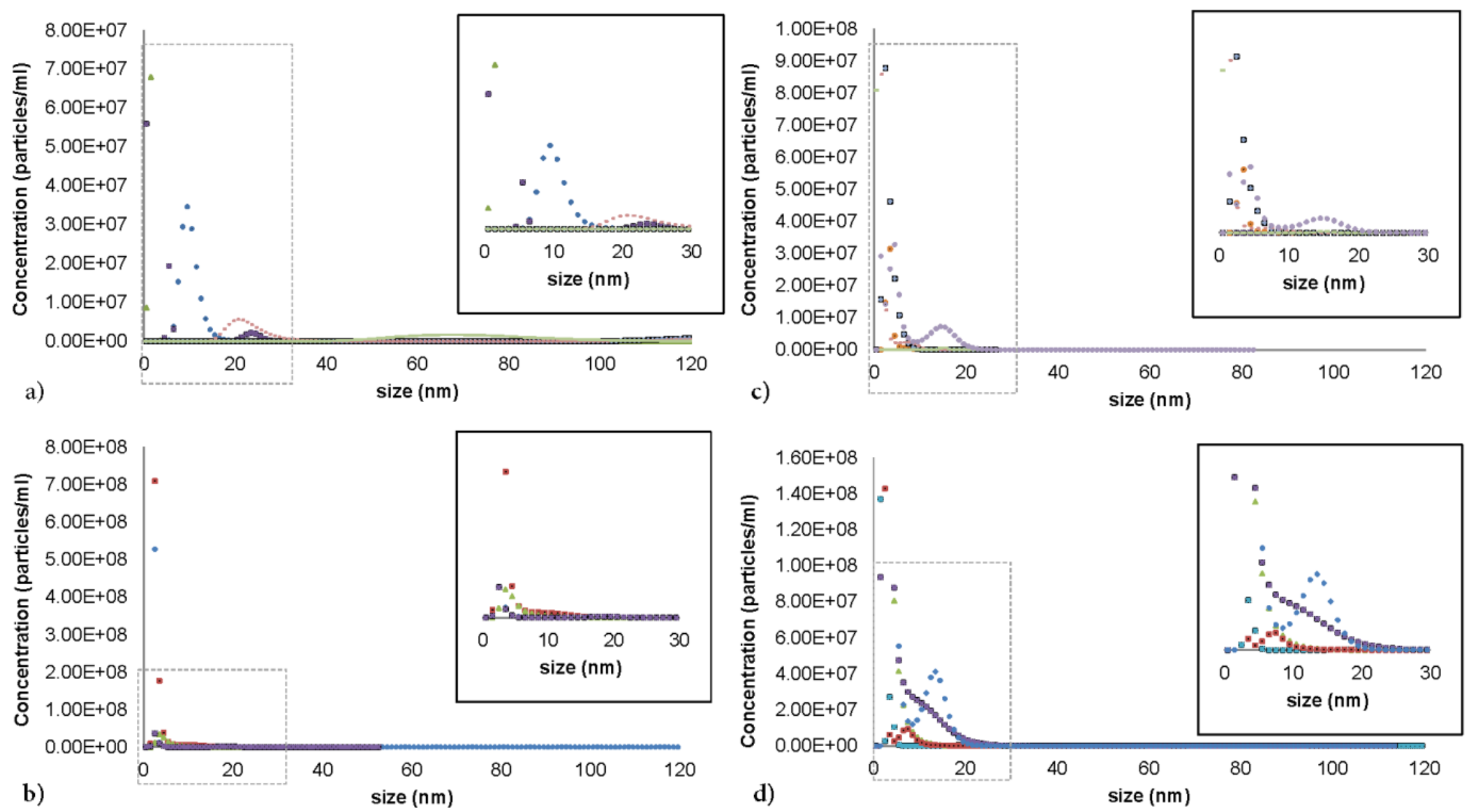

Figure 6: Results from particle analysis. Samples prepared with mineral base oil, a) Fresh by mixing, b) Fresh by sonication, c) Aged by mixing, d) Aged by sonication 